\title{
ESTEREÓTIPOS DE GÊNERO NAS IMAGENS DOS LIVROS DIDÁTICOS DE EDUCAÇÃO FÍSICA DO BRASIL
}

\author{
GENDER STEREOTYPES IN IMAGES OF PHYSICAL EDUCATION TEXTBOOKS IN \\ BRAZIL
}

\author{
ESTEREOTIPOS DE GÉNERO EN LAS IMÁGENES DE LOS LIBROS DIDÁCTICOS \\ DE EDUCACIÓN FÍSICA DE BRASIL
}

\author{
Alba González-Palomares*, Helena Altmann**, Ana Rey-Cao*
}

\begin{abstract}
Palavras-chave
Sexismo.

llustrações de livros. Ensino fundamental e médio.

Esportes.

Resumo: Este estudo analisa se existem estereótipos de gênero nas imagens de livros didáticos da Educação Física brasileira. Foram analisadas 929 fotografias de livros publicados entre 2006 e 2012 e destinados a estudantes do ensino fundamental e médio. Para a análise de conteúdo se utilizou uma adaptação ad hoc de um instrumento empregado em investigações precedentes. Os resultados mostram um ligeiro predomínio da representação de homens frente à de mulheres e muitas imagens de grupos mistos de homens e mulheres. As imagens reproduzem parcialmente os padrões hegemônicos que vinculam o tipo de prática corporal com o gênero. Os homens se associam com os esportes enquanto as mulheres se vinculam às atividades de fitness e condicionamento físico. $O$ âmbito competitivo e os esportes de elite são accessíveis tanto para homens como para mulheres e não existe vinculação do uso do espaço esportivo em função do gênero.
\end{abstract}

Keywords

Sexism.

Book illustrations.

Basic and Secondary

Education.

Sports.

\section{Palabras clave}

Sexismo.

llustraciones de

libros.

Educación primaria y

secundaria.

Deportes.

Abstract: This study examines whether or not Brazilian Physical Education textbooks contain images of gender stereotypes. It looked at 929 photographs of textbooks published between 2006 and 2012 to be used by Basic and Secondary Education students. Content analysis was conducted through an ad hoc adaptation of an instrument used in previous studies. Results show a slight predominance of the male representation over female, and many images of mixed groups. Images partially reproduce hegemonic patterns linking physical activity with gender. Men are associated to sports while women are linked to fitness activities. The competitive environment and elite sports are accessible to both men and women and there is no relation between gender and the use the sports space.

Resumen: Este estudio analiza si existen estereotipos de género en las imágenes de los libros didácticos de Educación Física brasileños. Se analizaron 929 fotografías de libros publicados entre 2006 y 2012 destinados a estudiantes de Enseñanza Fundamental y Media. Para el análisis de contenido se utilizó una adaptación ad hoc de un instrumento empleado en investigaciones precedentes. Los resultados muestran un ligero predominio de la representación de hombres frente a la de mujeres y muchas imágenes de grupos mixtos de ambos sexos. Las imágenes reproducen parcialmente los patrones hegemónicos que vinculan el tipo de actividad física con el género. Los hombres son asociados a los deportes, mientras que las mujeres son vinculadas a las actividades de fitness y preparación física. El ámbito competitivo y los deportes de élite son accesibles tanto para hombres como para mujeres y no existe vinculación del uso del espacio deportivo en función del género.
* Universidade de Vigo. Pontevedra. Espanha

E-mail: albagonzalez@uvigo.es; anacao@uvigo.es

** Universidade Estadual de Campinas. Campinas, SP, Brasil. E-mail: altmann@ @fef.unicamp.br

Recebido em: 19-05-2014 Aprovado em: 21-01-2015 (c) (1) (8) Licence 


\section{INTRODUÇÃO}

Nos últimos anos, foram publicados livros didáticos de Educação Física que tematizam os conteúdos dessa disciplina para seu ensino dentro das escolas. Neste estudo foram analisados o "Livro didático público" da Paraíba e do Paraná; as "Lições do Rio Grande. Referenciais curriculares. Caderno do aluno" do Rio Grande do Sul; os "Cadernos do aluno" de São Paulo e a "Coleção Cultura Corporal" da editora Ícone.

O livro de texto escolar é uma ferramenta de trabalho para o docente, um recurso didático facilitador da assimilação de conhecimentos para os estudantes e um recurso material de especificidade formal (MARTíNEZ, 2002). Os livros didáticos contêm imagens que exercem um papel educativo. As imagens publicadas nos livros didáticos são portadoras de currículo oculto (ACASO; NUERE, 2005). A quantidade de informação que chega ao alunado por meio das imagens e que se filtra na consciência coletiva sem reflexão prévia faz da linguagem icônica uma poderosa maneira para a reprodução de estereótipos. A imitação é um fenômeno fundamental para a existência, controle e direcionamento do social. As crenças se depositam de maneira gradual nas consciências individuais constituindo o vínculo necessário para a emergência de uma consciência coletiva. $O$ efeito da fotografia é uma analogia excelente deste processo porque consegue dissolver a polaridade entre realidade e sua reprodução, apagando a oposição entre substrato e representação (NOCERA, 2006).

A elaboração e aplicação dos livros didáticos na Educação Física escolar (EFe) requer uma análise prévia dos materiais (BOTELHO; NEIRA, 2014).

Este artigo é resultado de uma pesquisa que teve como objetivo analisar os estereótipos de gênero nas imagens de livros didáticos da Educação Física publicados no Brasil entre 2006 e 2012 e utilizados pelos estudantes do ensino fundamental e médio.

\section{REFERENCIAL TEÓRICO}

\subsection{Educação Física e estereótipos de gênero}

Os estereótipos são generalizações preconcebidas sobre os atributos ou características pessoais nos diferentes grupos sociais (COLÁS; VILLACIERVOS, 2007). Precisamente 0 gênero é conceitualizado como um elemento constitutivo prioritário das relações sociais entre os sexos. $O$ gênero é uma simbolização da diferença sexual que exerce um papel fundamental na organização e distribuição do poder (SCOTT, 1996). 0 feminino e o masculino, longe de ser uma realidade binária associada essencialmente a cada sexo, é "[...] a melhor fundada das ilusões coletivas" que atua impondo atribuições a cada sexo e colabora a uma interessada distribuição do poder (BOURDIEU, 2008, p. 232).

Os estereótipos de gênero são muito visíveis no âmbito da cultura corporal de jovens e adolescentes (COLÁS; VILLACIERVOS, 2007). A atribuição que realizam os jovens de atividades físicas específicas para homens e mulheres e a identificação da competição como um âmbito masculino (BLÁNDEZ; FERNÁNDEZ; SIERRA, 2007) são algumas das suas manifestações. Os esportes podem ser classificados como possuidores de características masculinas - futebol, halterofilismo - ou características femininas - nado sincronizado, dança (MELO; GIOVANI; TRÓCCOLI, 2004). 
Esses estereótipos podem estar condicionando uma prática corporal diferenciada para homens e mulheres. A pesquisa realizada por Salles-Costa et al. (2003) sobre as atividades físicas de lazer praticadas por funcionários técnico-administrativos de uma universidade do Estado do Rio de Janeiro constatou que as mulheres praticam caminhada, ginástica, dança e hidroginástica. Os homens se relacionam com a prática de futebol, corrida, tênis e musculação. $\mathrm{Na}$ Espanha o estudo de Martín et al. (2009) aporta dados similares. As mulheres realizam atividades como ginástica aeróbica, expressão corporal, dança, natação, enquanto os homens se relacionam mais com esportes - futebol, ciclismo, natação e tênis - que funcionam como dispositivos de normalização da masculinidade heterocentrada e de uma visão do corpo concebida como máquina de rendimento (re)produtivo (VIDIELLA et al., 2010). A desigualdade de gênero associada ao campo desportivo também se estende a atividades e esportes de aventura identificados como atividades exclusivas para homens, onde a presença feminina é escassa (SCHWARTZ et al., 2013).

O uso do espaço e as práticas corporais nele vivenciadas também são suscetíveis de diferenças em relação ao gênero. Vilanova e Soler (2008) destacam que o desenho urbanístico do espaço público na Espanha não leva em conta as necessidades das mulheres, e estimula a reprodução de condutas estereotipadas no seu uso e a escassa presença de mulheres no mesmo. Assim, na Espanha, as mulheres são as clientes principais das academias de ginástica - espaços internos -, enquanto os homens são o público majoritário dos estádios, das instalações ao ar livre e dos parques - espaços externos (MARTíNEZ DEL CASTILLO; PUIG, 2002). Estudos realizados no Brasil também encontraram diferenças de gênero na ocupação do espaço escolar destinado a atividades físicas e também ao pátio de recreio. Os meninos ocupam espaços maiores destinados a esportes coletivos, enquanto meninas, espaços menores próximos ao edifício (ALTMANN, 1998; WENETZ; STIGGER, 2006).

\subsection{A pesquisa sobre gênero nos livros de texto em Educação Física escolar (EFe)}

A análise de livros didáticos de EFe é muito escassa (BOTELHO; NEIRA, 2014). No Brasil, as investigações nos livros de texto em relação ao gênero se concentraram em analisar outras disciplinas, como Ciências, História, Matemática, Línguas estrangeiras, entre outras. Não foram localizadas pesquisas sobre livros didáticos de EFe.

A pesquisa de Oliveira (2008) examinou 37 livros didáticos de Línguas estrangeiras. Concluiu que as ilustrações examinadas apresentam maior incidência de imagens masculinas que femininas.

Dados similares encontraram Casagrande e Carvalho (2006) na análise de 18 livros de Matemática para 5a e 6⿳亠丷厂 séries. Estas autoras identificaram que a representação de meninos é mais frequente que a de meninas.

Pires (2004) analisou ilustrações presentes nos livros didáticos de Língua Portuguesa para 4⿳亠丷a série usados na década de 1980 e no período entre 1998 e 2002. Esta autora identificou que os livros analisados em sua maioria dão maior visibilidade ao gênero masculino, tanto em textos quanto em ilustrações.

Para analisar a perspectiva de gênero nos manuais de EFe tomamos como referência estudos prévios realizados na Espanha. Esses estudos analisaram os estereótipos de gênero 
presentes nas imagens dos livros didáticos publicados na Espanha para estudantes entre 6 e 12 anos (MOYA-MATA et al., 2013) e de 12 a 16 anos (GONZÁLEZ, 2005; TÁBOAS-PAIS; REY-CAO, 2012).

$\mathrm{Na}$ análise dos livros de ensino primário, Moya Mata et al. (2013) apuraram que a categoria mais representada foi grupo misto (38.8\%), seguido da categoria homem $(26.7 \%)$ e, em terceiro lugar, a categoria mulher (23.3\%).

A investigação feita por Táboas-Pais e Rey-Cao (2012) revelou que quase a metade das fotografias publicadas nos livros de ensino secundário (49,49\%) são formadas exclusivamente por homens. Esse dado vai ao encontro da pesquisa de González (2005), que evidenciou a desigualdade entre homens e mulheres nesses materiais.

Táboas-Pais e Rey-Cao (2012) também identificaram que nas fotografias os homens realizam prática esportiva na maioria das ocasiões, sobretudo esportes coletivos, como futebol, basquetebol, rúgbi. Por outro lado, as mulheres praticam outros tipos de atividades físicas não desportivas, como as atividades de fitness ou as artísticas. Os dados obtidos manifestam a hegemonia masculina no âmbito da competição, já que os homens são fotografados com frequência em situações competitivas, enquanto as mulheres raras vezes aparecem nesse âmbito.

Em relação ao nível de profissionalização que se representa nas imagens, Táboas-Pais e Rey-Cao (2012) observam que nas fotografias dos livros de EFe os homens aparecem em $69,2 \%$ das imagens de prática de esportes de elite, enquanto as mulheres aparecem em 23,9\% delas. Relaciona-se desta forma os homens com o esporte de elite e do alto rendimento.

Este artigo tem como objetivo geral analisar se existem estereótipos de gênero nas imagens dos livros didáticos da Educação Física brasileira. As hipóteses do estudo são: 1. A representação dos homens é superior à das mulheres. 2. As mulheres realizam práticas corporais de tipo artístico, de interiorização ou de fitness e condicionamento físico, enquanto os homens praticam esportes ou práticas corporais na natureza. 3. As mulheres praticam esportes individuais, enquanto os homens praticam esportes coletivos. 4. As práticas corporais realizadas por mulheres estão fora do âmbito competitivo, enquanto a dos homens localiza-se no âmbito da competição. 5. 0 espaço em que aparecem as mulheres é o interior, enquanto 0 dos homens é o exterior. 6 . 0 nível de prática das mulheres é fora da elite esportiva, enquanto 0 dos homens é 0 alto rendimento.

\section{METODOLOGIA}

O estudo é de tipo empírico, descritivo e comparativo, e emprega a análise de conteúdo (NEUENDORF, 2011) como técnica central da investigação. As fotografias editadas nos livros didáticos de EFe para o ensino fundamental e médio são as unidades de amostragem.

\subsection{Amostra}

A amostra está formada por 929 fotografias que pertencem a 36 livros didáticos de EFe publicados no Brasil. A seleção da amostra foi intencional ou de conveniência. Se analisaram os livros destinados a estudantes do ensino fundamental e médio publicados entre os anos 2006 e 2012, aos que se teve fácil acesso. Estão incluídas as propostas curriculares dos estados da 
Paraíba, Paraná, Rio Grande do Sul e São Paulo e os livros didáticos publicados por uma editora privada, Ícone - Quadro 1. Não foram analisadas fotografias sem a presença de uma figura humana e aquelas em que não era possível distinguir o tipo de prática corporal realizada.

Do total de imagens publicadas nos livros didáticos - N=929 -, 104 imagens - 11,2\% do total - foram descartadas de acordo com os critérios estabelecidos. Portanto, para a descrição da variável sexo-agrupação $n=825$.

Quadro 1 - Livros didáticos de EFe do Brasil

\begin{tabular}{|l|l|c|l|c|}
\hline Livro Didático & Título & $\begin{array}{l}\text { Ano de } \\
\text { Publicação }\end{array}$ & Nível Escolar & Imagens \\
\hline Paraíba (PB) & Livro didático público da Paraíba & 2012 & $\begin{array}{l}\text { Ensino funda- } \\
\text { mental }\end{array}$ & 65 \\
\hline Paraná (PR) & Livro didático público do Paraná & 2007 & Ensino médio & 27 \\
\hline $\begin{array}{l}\text { Rio Grande do Sul } \\
\text { (RS) }\end{array}$ & $\begin{array}{l}\text { Liçães do Rio Grande. Referenciais } \\
\text { Curriculares-Caderno do aluno }\end{array}$ & 2009 & $\begin{array}{l}\text { Ensino funda- } \\
\text { mental }\end{array}$ & 111 \\
\hline São Paulo (SP) & Cadernos do aluno & 2010 & $\begin{array}{l}\text { Ensino funda- } \\
\text { mental e médio }\end{array}$ & 375 \\
\hline Editora Ícone (IC) & $\begin{array}{l}\text { Coleção Cultura Corporal. Quatro } \\
\text { volumes. }\end{array}$ & $2008-2011$ & $\begin{array}{l}\text { Ensino funda- } \\
\text { mental e médio }\end{array}$ & 351 \\
\hline
\end{tabular}

Fonte: Dados das autoras

\subsection{Variáveis}

As imagens foram codificadas por sexo-agrupação - condições de aparência das pessoas protagonistas da imagem que permitiam estabelecer diferenças biológicas entre homens, mulheres e grupos de homens-mulheres; o tipo de prática corporal - as diferentes denominações das expressões corporais e/ou esportes; 0 âmbito de prática - contexto onde se realiza a prática; espaço - entorno físico onde se pratica a atividade; e nível - nível de dedicação e/ou profissionalização. A variável independente deste estudo é o sexo-agrupação.

No Quadro 2, explicitam-se as definições dos indicadores que operacionalizam cada uma das variáveis e que foram aplicadas no instrumento de análise de conteúdo.

\section{Quadro 2 - Sistema de categorias}

\begin{tabular}{|ll|}
\hline Categorias/Indicadores & Definições operativas \\
\hline 1.1. Sexo-agrupação & \\
\hline $\begin{array}{l}\text { 1.1.1. Homens } \\
\text { 1.1.2. Mulheres }\end{array}$ & Uma ou mais pessoas cuja característica básica é que são homens. \\
1.1.3. Grupo de homens-mulheres & Duas ou mais pessoas dos dois sexos. \\
\hline 2.1. Tipo de prática corporal & \\
\hline $\begin{array}{l}\text { 2.1.1. Esportes coletivos } \\
\text { 2.1.2. Esportes individuais }\end{array}$ & Esportes em equipe, em colaboração/oposição. P. ex.: handebol. \\
& Esportes onde a participação é individual e os esportes de adversário. \\
2.1.3. Artísticas & P. ex.: natação. \\
& Práticas que utilizam o corpo como meio de expressão artística. P. ex.: \\
teatro. Também aquelas imagens que mostram a expressão facial ou \\
2.1.4. Fitness e condicionamento \\
físico & gestual como o objeto fundamental da ação. \\
\hline
\end{tabular}




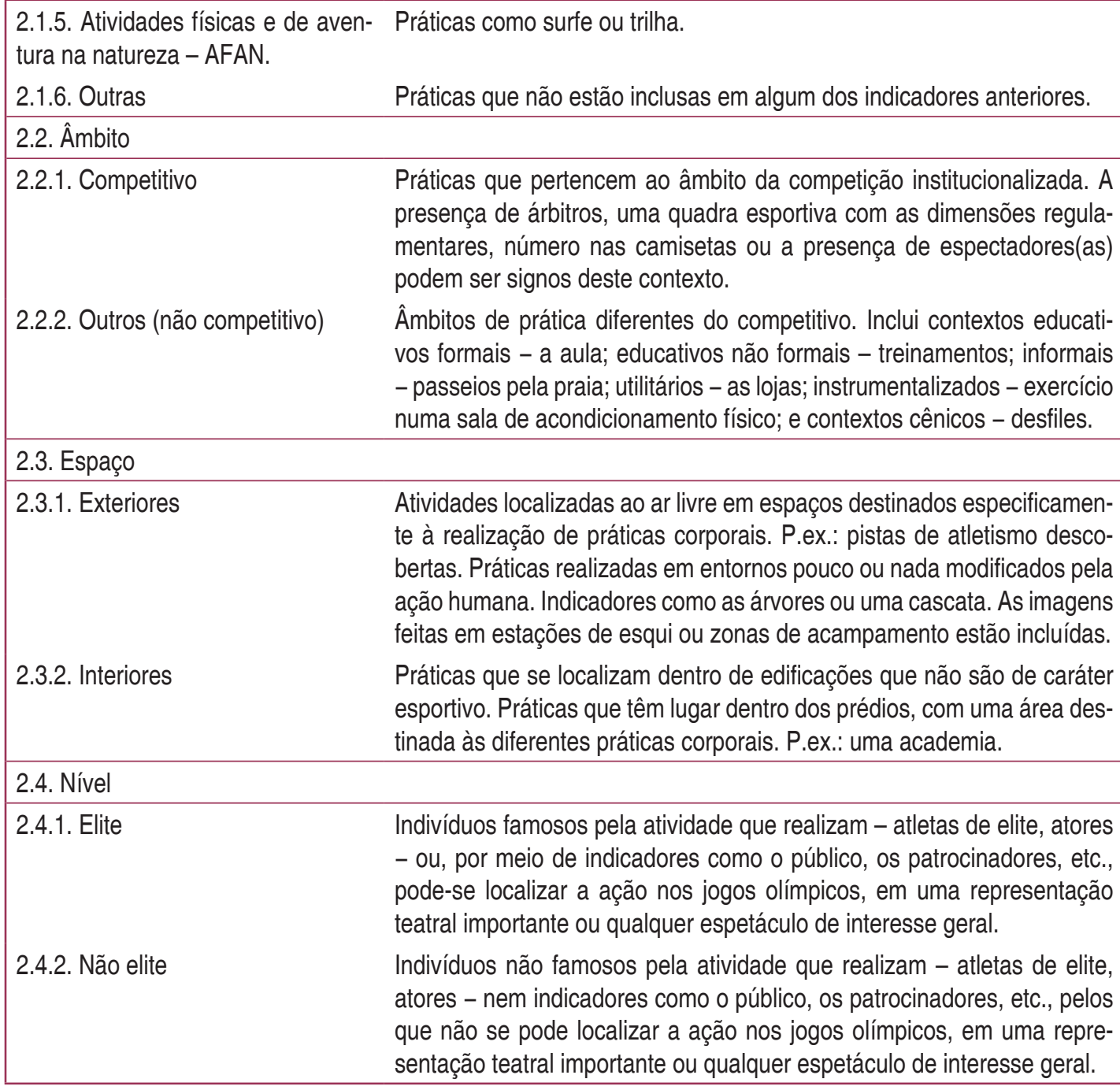

Fonte: Dados das autoras

\subsection{Procedimento}

Utilizou-se uma adaptação do sistema de categorias proposto por Táboas-Pais (2009). A redefinição operativa de cada uma das categorias e indicadores do sistema foi guiada pela revisão da literatura com a intenção de otimizar o trabalho e aproveitar os resultados de estudos anteriores (NEUENDORF, 2011). Seguindo as indicações das conclusões da tese doutoral desta autora, modificou-se a categoria âmbito de prática, ampliando e especificando mais contextos de prática. Antecedendo a recopilação dos dados, se comprovou a adequação da categoria elaborada ad hoc, ou seja, sua validez, fiabilidade, objetividade e sua utilidade prática. Este processo organizou-se em três fases:

a) Prova-piloto. Efetuada pela investigadora principal para valorar a credibilidade ou validez da ferramenta com as novas mudanças efetuadas. Extraiu-se uma amostra de 238 imagens, que não pertenciam à amostra final analisada, através de uma amostragem aleatória simples.

b) Consulta a expertos(as). Três expertos(as) em análise de conteúdo colaboraram nesta tarefa para corroborar a credibilidade do instrumento. Solicitaram-se suas opiniões em relação a: adequação do sistema de categorias ao objeto de estudo; exaustividade e mútua exclusividade das categorias; clareza na redação das definições; e minimização da subjetividade do(a) observador(a). A informação se 
recolheu mediante a escala de Likert, com valores compreendidos entre 1 - muito em desacordo - e 5 - muito de acordo - e informação qualitativa complementária. A maioria dos itens recebeu uma valoração de 4 ou 5 pelos(as) três expertos(as).

c) Prova intercodificadores. Colaboraram nesta tarefa de validação três expertas em análise de conteúdo. A observação e codificação das imagens para a prova intercodificadores se realizou de forma individual sobre um total de 50 imagens. 0 critério de seleção foi que todos os indicadores do sistema de categorias deviam ser codificados. Os valores do alfa de Krippendorff - >.80 - obtidos confirmam a confiabilidade do sistema de categorias. Uma vez finalizada a codificação da amostra deste trabalho, 10\% da amostra - 93 imagens - foi codificada por um codificador externo e se calculou novamente 0 alfa de Krippendorff para averiguar a confiabilidade da codificação final. Para esta segunda prova de confiabilidade levou-se a cabo uma amostragem aleatória simples para a seleção das imagens. O alfa de Krippendorff calculado também obteve alta confiabilidade - >.80.

\subsection{Análise e processamento dos dados}

As imagens foram analisadas através da observação direta do livro didático. As fotografias sobre as quais havia dúvidas acerca do tipo de prática corporal representado na imagem foram codificadas através da informação aportada pelo texto ou paratexto que as acompanhava. A análise estatística se realizou com a ajuda do software SPSS 19.0. Realizaram-se uma análise descritiva univariante e medidas de associação entre as diferentes variáveis - bivariante. Empregaram-se tabelas de contingência e resíduos tipificados corrigidos; e aplicou-se o teste Chi-quadrado de Pearson com um nível de significação estabelecido no 5\% - $\square=0,05$.

\section{RESULTADOS}

Hipótese 1. Na análise das imagens - Tabela 1 -, observa-se que a representação de imagens exclusivamente formadas por homens - 38,6\% - é a mais frequente, seguido do indicador grupos de homens-mulheres - 35,2\% -, e em terceiro lugar, as imagens representadas exclusivamente por mulheres - 26,2\%. Nos estados do Paraná, do Rio Grande do Sul e de São Paulo os homens são os mais representados - 75,0\%, 55,8\% e 50,9\%, respectivamente. As imagens formadas por mulheres têm porcentagens inferiores - 15,0\%, 38,4\% e 36,4\%, respectivamente -, sendo o caso mais notável o do estado do Paraná. No estado da Paraíba existe uma representação igualitária para os indicadores mulheres e os grupos de homens-muIheres - 33,9\% -, sendo a porcentagem de imagens de homens de 32,1\%. Na editora Ícone (IC) os grupos de homens-mulheres são os mais representados, com uma porcentagem de $64,4 \%$. Os homens são representados em $22,2 \%$ e as mulheres em $13,4 \%$. De maneira global, todos os livros didáticos representam em maior porcentagem as imagens de homens que as de mulheres - Gráfico 1.

Tabela 1 - Frequências e porcentagens das imagens dos livros de EFe em função do sexo-agrupação

\begin{tabular}{lll}
\hline Sexo-agrupação & $\mathrm{N}$ & $\%$ \\
\hline Homens & 318 & 38,6 \\
Mulheres & 216 & 26,2 \\
Grupo de homes-mulheres & 291 & 35,2 \\
\hline
\end{tabular}

Fonte: Dados das autoras 
Gráfico 1 - Sexo-agrupação dos sujeitos representados nas imagens dos livros didáticos, em função do Estado

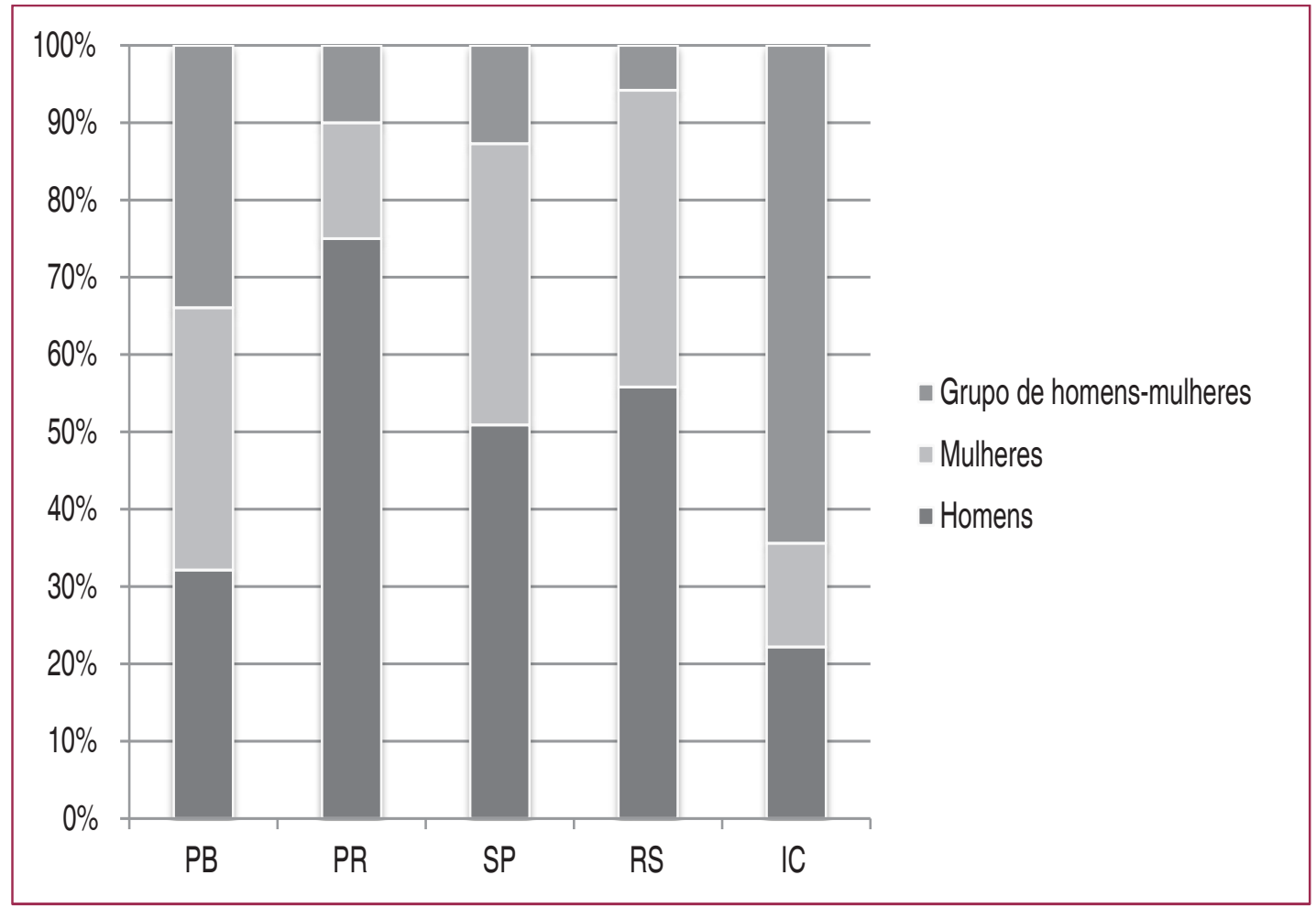

Fonte: Dados das autoras

Hipótese 2 e hipótese 3. Os resultados obtidos na análise bivariante mostram a relação entre o tipo de prática corporal representado nas imagens e o sexo dos sujeitos. 0 teste Chi-quadrado de Pearson - $X^{2}$ - obteve um nível de significância de .000 o qual corrobora que 0 tipo de prática corporal representado nas imagens varia em função do sexo do sujeito que 0 pratica $-X^{2}=112,087, g l=8, p<.000$.

Na Tabela 4 se observa que $66,2 \%$ das imagens que mostram esportes coletivos pertencem exclusivamente a homens, enquanto 16,9\% pertencem a mulheres. Nos esportes individuais, $47,5 \%$ das imagens representam homens e $25,7 \%$, mulheres.

As porcentagens da tabela de contingência revelam que aquelas imagens que mostram esportes estão relacionadas em maior proporção com o gênero masculino que com o gênero feminino. Não aparece nenhuma imagem relacionada com as atividades físicas na natureza e o gênero feminino. Em contraste, as mulheres são representadas mais frequentemente em atividades de fitness e condicionamento físico. As porcentagens para as atividades artísticas são muito similares para os dois gêneros.

A Tabela 4 mostra que os resíduos corrigidos ratificam a relação entre as variáveis. Os exemplos mais claros são aqueles que relacionam os homens com os esportes coletivos: residual 7.0. Este valor indica uma relação positiva entre ser homem e praticar esportes coletivos. Os residuais também mostram uma relação positiva entre ser mulher e praticar atividades de fitness e condicionamento físico: residual 5.0. Em contraste, se observa uma relação negativa entre ser mulher e praticar esportes coletivos - valor 2.6 - e entre ser homem e praticar atividades artísticas - valor 3.7 - ou atividades de fitness e condicionamento físico - valor 4.4 . 
Tabela 4 - Tabela de contingência para as variáveis sexo-agrupação e tipo de prática corporal

\begin{tabular}{|c|c|c|c|c|}
\hline \multirow{2}{*}{ Tipo de prática corporal } & & \multicolumn{3}{|c|}{ Sexo-agrupação } \\
\hline & & Homens & Mulheres & $\begin{array}{c}\text { Grupo de } \\
\text { homens-mulheres }\end{array}$ \\
\hline \multirow{3}{*}{ Esportes coletivos } & Frequência & 86 & 22 & 22 \\
\hline & \% de tipo de prática corporal & $66,2 \%$ & $16,9 \%$ & $16,9 \%$ \\
\hline & Resíduos corrigidosa & 7,0 & $-2,5$ & $-4,8$ \\
\hline \multirow{3}{*}{ Esportes individuais } & Frequência & 131 & 71 & 74 \\
\hline & \% de tipo de prática corporal & $47,5 \%$ & $25,7 \%$ & $26,8 \%$ \\
\hline & Resíduos corrigidos ${ }^{a}$ & 3,7 & $-0,3$ & $-3,4$ \\
\hline \multirow{3}{*}{ Artísticas } & Frequência & 39 & 38 & 75 \\
\hline & \% de tipo de prática corporal & $25,7 \%$ & $25,0 \%$ & $49,3 \%$ \\
\hline & Resíduos corrigidos ${ }^{a}$ & $-3,6$ & $-0,4$ & 4,1 \\
\hline \multirow{3}{*}{$\begin{array}{l}\text { Fitness e } \\
\text { condicionamento físico }\end{array}$} & Frequência & 12 & 39 & 27 \\
\hline & \% de tipo de prática corporal & $15,4 \%$ & $50,0 \%$ & $34,6 \%$ \\
\hline & Resíduos corrigidos ${ }^{a}$ & $-4,4$ & 5,0 & $-0,1$ \\
\hline \multirow{3}{*}{ Outras } & Frequência & 52 & 47 & 92 \\
\hline & \% de tipo de prática corporal & $27,2 \%$ & $24,6 \%$ & $48,2 \%$ \\
\hline & Resíduos corrigidos ${ }^{a}$ & $-3,7$ & $-0,6$ & 4,3 \\
\hline
\end{tabular}

$-X^{2}=112,087, g=8, p<.000$

a Os resíduos corrigidos maiores de 1,96 - valor absoluto - indicam que há mais casos, se é positivo, ou menos, se é negativo, dos que deveria haver na célula se as variáveis foram independentes.

Fonte: Dados das autoras

Hipótese 4. 0 teste estatístico do $\mathrm{X}^{2}$ para as variáveis obteve um $p$-valor de .000 , o qual confirma que o âmbito ou contexto onde se localiza a imagem depende do sexo-agrupação do sujeito representado $-X^{2}=137,339, \mathrm{gl}=2, \mathrm{p}<.000$. O teste estatístico $\mathbf{X}^{2}$ revelou que, com um nível de significação fixado a 5\%, houve dependência estatisticamente significativa entre as variáveis sexo-agrupação e âmbito de prática em todos os estados e na editora analisados. A Tabela 5 mostra que na competição institucionalizada aparecem 45,6\% dos homens, 35,8\% das mulheres e $2,2 \%$ dos grupos de homens e mulheres. Os resíduos corrigidos mostram uma relação positiva entre ser homem e fazer prática corporal no âmbito competitivo - resíduo 8.8. A relação entre ser mulher e realizar atividades relacionadas com a competição também é positiva, mas em menor escala que homens - resíduo 3.2. Enquanto a relação entre grupos mistos e âmbito competitivo é negativa - resíduo 11.5.

Tabela 5 - Tabela de contingência para as variáveis sexo-agrupação e âmbito de prática

\begin{tabular}{llccc}
\hline \multirow{2}{*}{ Âmbito de prática } & & \multicolumn{3}{c}{ Sexo-agrupação } \\
\cline { 3 - 4 } & Frequência & Homens & Mulheres & $\begin{array}{c}\text { Grupo de } \\
\text { homens-mulheres }\end{array}$ \\
\cline { 3 - 4 } Competitivo & \% de âmbito & 115 & 58 & 6 \\
& Resíduos corrigidos & & $35,8 \%$ & $2,2 \%$ \\
Outros - não competitivo & \% de âmbito & $137,6 \%$ & 104 & $-11,5$ \\
& Frequência & $54,4 \%$ & $64,2 \%$ & 264 \\
& Resíduos corrigidos & & $97,8 \%$ \\
& & $-8,8$ & $-3,2$ & 11,5 \\
\hline
\end{tabular}

$-X^{2}=137,339, g \mid=2, p<.000$

a Os resíduos corrigidos maiores de 1,96 - valor absoluto - indicam que há mais casos, se é positivo, ou menos, se é negativo, dos que deveria haver na célula se as variáveis foram independentes.

Fonte: Dados das autoras 
Hipótese 5. A análise do Chi-quadrado de Pearson - $\mathbf{X}^{2}$ - para as variáveis espaço e sexo-agrupação mostrou um valor associado de .836, confirmando que ambas variáveis são independentes em um nível de confiança de $95 \%$. A probabilidade que tem um sujeito de aparecer num espaço exterior ou interior é independente de qual seja o seu sexo.

Hipótese 6. A análise estatística do teste Chi-quadrado de Pearson - $\mathbf{X}^{2}-$ aplicou-se para as variáveis sexo-agrupação e nível. Obteve-se um valor associado de $.000-\mathbf{X}^{2}=70,651$, $g l=2, p<.000$. Há uma relação estatisticamente significativa entre 0 nível que envolve a prática esportiva e o sexo-agrupação do sujeito que a pratica. Na Tabela 6 se observa que na elite desportiva aparecem $24,8 \%$ dos homens, $21,9 \%$ das mulheres e 1,4\% dos grupos de homens e mulheres. Os resíduos corrigidos mostrados na Tabela 6 indicam que o número de imagens mostrando homens em atividades de alto rendimento é mais alto do que caberia esperar se as variáveis fossem independentes - resíduo 5,6. 0 mesmo acontece no caso das mulheres - resíduo 3,0.

Tabela 6 - Tabela de contingência para as variáveis sexo-agrupação e nível

\begin{tabular}{llccc}
\hline \multirow{2}{*}{ Nível } & & \multicolumn{3}{c}{ Sexo-agrupação } \\
\cline { 3 - 5 } & Frequência & Homens & Mulheres & $\begin{array}{c}\text { Grupo de } \\
\text { homens-mulheres }\end{array}$ \\
\cline { 3 - 5 } Elite & \% de elite & 74 & 46 & 4 \\
& Resíduos corrigidos & $24,8 \%$ & $21,9 \%$ & $1,4 \%$ \\
& Frequência & 5,6 & 3,0 & $-8,4$ \\
\multirow{2}{*}{ Não elite } & \% de elite & 224 & 164 & 287 \\
& Resíduos corrigidos & & & \\
& & $75,2 \%$ & $78,1 \%$ & $98,6 \%$ \\
& & $-5,6$ & $-3,0$ & 8,4 \\
\hline
\end{tabular}

$-X^{2}=70,651, g l=2, p<.000-$

a Os resíduos corrigidos maiores de 1,96 - valor absoluto - indicam que há mais casos, se é positivo, ou menos, se é negativo, dos que deveria haver na célula se as variáveis foram independentes.

Fonte: Dados das autoras

\section{DISCUSSÃO}

Os livros didáticos do Brasil representam quase de forma igualitária modelos masculinos e grupos de homens e mulheres nas suas imagens. A presença de mulheres continua sendo inferior à dos homens, se bem que há maior representação de mulheres que em estudos prévios. Casagrande e Carvalho (2006), González (2005), Oliveira (2008) e Pires (2004) evidenciaram uma maior frequência de aparição de homens nos livros didáticos do que aquelas encontradas nesta pesquisa com livros didáticos EFe. Esta pesquisa concorda com a maior presença de homens encontrada por Táboas-Pais e Rey-Cao (2012) nas fotografias publicadas nos livros de EFe da Espanha. Mesmo assim, a porcentagem de presença feminina neste estudo foi consideravelmente maior, já que estas autoras revelaram que aproximadamente a metade das fotografias representava exclusivamente homens. Os dados apresentados por Moya-Mata et al. (2013) não se confirmam neste estudo. Estas autoras evidenciaram uma maior presença de grupos mistos nos livros analisados.

Dentro dos diferentes estados existem diferenças. Os estados do Paraná, de São Paulo e do Rio Grande do Sul representam majoritariamente os homens nas imagens dos seus livros. $O$ estado da Paraíba apresenta de forma igualitária homens, mulheres e grupos mistos. 
A editora privada Ícone apresenta em mais da metade das suas fotografias imagens que representam grupos de homens e mulheres realizando atividades de forma conjunta.

Os livros didáticos reproduzem os estereótipos tradicionais em torno da atribuição de um tipo de prática corporal para cada gênero. Aquilo que é expresso nas imagens coincide com as crenças dos adolescentes que situam os homens em atividades de equipe e de oposição, e as mulheres em atividades individuais (BLÁNDEZ; FERNÁNDEZ; SIERRA, 2007); e com a análise dos livros didáticos da Espanha (TÁBOAS-PAIS; REY-CAO, 2012), que revelou esta mesma associação.

A vinculação das AFAN com o gênero masculino e das atividades artísticas com 0 gênero feminino não foi constatada neste estudo. Os resultados divergem do apontado por Táboas-Pais e Rey-Cao (2012) nos livros didáticos de EFe da Espanha. Assim mesmo, estes dados não coincidem com os maiores índices de prática do gênero feminino nas artísticas e expressivas (MARTíN et al., 2009; SALLES-COSTA et al., 2003).

No que concerne ao âmbito de prática, os resultados indicam que os livros didáticos não reproduzem os estereótipos tradicionais que vinculam os homens ao âmbito da competição institucionalizada e as mulheres a outros tipos de âmbitos localizados fora do âmbito competitivo.

O âmbito competitivo deixa de ser um terreno delimitado para o mundo masculino e passa a ser um campo aberto tanto para homens como para mulheres. Estes dados contradizem os resultados encontrados por Táboas-Pais e Rey-Cao (2012). A desportividade e a instrumentalização da cultura corporal parecem estar se estendendo às mulheres. A presença majoritária de grupos de homens e mulheres em contextos não competitivos pode ser explicada pela impossibilidade regulamentária de participação em esportes de competição, dado que representações mistas se contextualizam em âmbitos não competitivos.

Em relação ao espaço de prática em função do gênero, os resultados deste estudo não concordam com a literatura revisada em relação ao uso esportivo do espaço público em função do gênero (MARTíNEZ DEL CASTILLO; PUIG, 2002; VILANOVA; SOLER, 2008). Em todos os livros didáticos o gênero e o espaço de prática são independentes entre si, resultados que diferem dos dados aportados por Táboas-Pais e Rey-Cao (2012) na análise dos estereótipos nos livros da Espanha.

Finalmente, no que tange ao nível de prática, os resultados desta investigação não coincidem com os dados obtidos por Táboas-Pais e Rey-Cao (2012). Estas autoras descobriram que nos livros didáticos de EFe as práticas realizadas na elite desportiva estavam relacionadas com o mundo masculino. Os dados deste estudo revelam que as atividades realizadas com um alto nível de profissionalização estão representadas tanto por homens como por mulheres.

\section{CONCLUSÃO}

As imagens dos livros de texto de EFe mostram um ligeiro predomínio de representação de homens frente à de mulheres e muitas imagens de grupos mistos de homens e mulheres.

As imagens presentes nos livros didáticos do Brasil reproduzem parcialmente os padrões hegemônicos que vinculam o tipo de prática corporal ao gênero. Transmite-se uma mas- 
culinidade hegemônica associada aos esportes, tanto coletivos como individuais, enquanto a feminidade se vincula às atividades de fitness e condicionamento físico.

Outros estereótipos menos evidentes, como pode ser a vinculação entre homens-AFAN, mulheres-atividades artísticas, não são reproduzidos nas imagens dos livros didáticos.

As imagens mostram que tanto o âmbito competitivo como os esportes de elite são acessiveis tanto para mulheres quanto para homens, afastando-se assim do estereótipo tradicional que associa o mundo da competição e o alto rendimento como reserva para os homens.

O estereótipo tradicional que vincula o uso do espaço esportivo em função do gênero também não é reproduzido nas imagens dos livros didáticos do Brasil.

Este estudo somente examina os livros de texto de EFe do Brasil. Seria interessante realizar uma comparação para contrastar diferenças e semelhanças na reprodução dos estereótipos de gênero em outros países.

\section{REFERÊNCIAS}

ACASO, María; NUERE, Silvia. El curriculum oculto visual: aprender a obedecer a través de la imagen. Arte, Individuo y Sociedad, Madrid, v. 17, p. 205-218, 2005.

ALTMANN, Helena. Rompendo fronteiras de gênero: Marias (e) homens na Educação Física. 1998. 110 f. Dissertação (Mestrado) - Curso de Pós-graduação em Educação, UFMG, Belo Horizonte, 1998. BERGOLATO, Roseli Aparecida. Cultura corporal da dança: livro do professor e do aluno. 3. ed. São Paulo: Ícone, 2008a.

BERGOLATO, Roseli Aparecida. Cultura corporal da ginástica: livro do professor e do aluno. 4. ed. São Paulo: Ícone, 2011.

BERGOLATO, Roseli Aparecida. Cultura corporal do esporte: livro do professor e do aluno. 2. ed. São Paulo: Ícone, 2008b.

BERGOLATO, Roseli Aparecida. Cultura corporal do jogo: livro do professor e do aluno. 3. ed. São Paulo: Ícone, 2008c.

BLÁNDEZ, Julia; FERNÁNDEZ, Emilia; SIERRA, Miguel Ángel. Estereotipos de género, actividad física y escuela: La perspectiva del alumnado. Profesorado: Revista de currículum y formación del profesorado, Granada, v. 11, n. 2, p. 1-21. 2007.

BOTELHO, Rafael; NEIRA, Marcos. Análisis de libros de texto de Brasil y en España: una introducción al tema en el área de Educación Física. Movimento, Porto Alegre, v. 20, n. 2, p. 659-685, 2014.

BOURDIEU, Pierre. El sentido práctico. Madrid: Siglo XXI, 2008.

CASAGRANDE, Lindamir; CARVALHO, Marília. In: REUNIÃO ANUAL DA ANPED - EDUCAÇÃO, CULTURA E CONHECIMENTO NA CONTEMPORANEIDADE: DESAFIOS E COMPROMISSOS, 29., 2006. Educando as novas gerações: representações de gênero nos livros didáticos de Matemática. Caxambu, 2006. Disponível em:< http://www.anped.org.br/reunioes/29ra/trabalhos/trabalho/GT232066--Int.pdf >. Acesso em: 17 nov. 2014.

COLÁS, Pilar; VILLACIERVOS, Patricia. La interiorización de los estereotipos de género en jóvenes y adolescentes. Revista de Investigación Educativa, Murcia, v. 25, n. 1, p. 35-58, 2007.

GONZÁLEZ, Marta. ¿Tienen sexo los contenidos de la Educación Física Escolar? Transmisión de estereotipos de sexo a través de los libros de texto en la etapa de secundaria. Revista Internacional de Medicina y Ciencias de la Actividad Física y el Deporte, Madrid, v. 5, n. 18, p. 77-88, jun. 2005. 
MACIEIRA, Jeimison; CUNHA, Fernando José; XAVIER NETO, Lauro (Org.). Livro didático público: educação física. João Pessoa: Editora Universitária da UFPB, 2012.

MARTÍN, María et al. Las Actividades de Expresión Corporal y Danza en la Práctica de Actividades Físicas de las Españolas. In: CONGRESO INTERNACIONAL DE CULTURA Y GÉNERO: LA CULTURA EN EL CUERPO, 1., 2009, Alicante. Anais...Alicante, 2009. Disponível em: <http://oa.upm. es/5571/1/INVE MEM 2009 65983.pdf> Acesso em: 14 nov. 2014.

MARTÍNEZ DEL CASTILLO, Jesús; PUIG, Núria. Espacio y tiempo en el deporte. In: GARCÍA, M.; PUIG, N.; LAGARDERA, F. Sociología del deporte. 2. ed. Madrid: Alianza, 2002, p. 151-177.

MARTÍNEZ, Jaume. Políticas del libro de texto escolar. Madrid: Ediciones Morata, 2002.

MELO, Gislane; GIOVANI, Adriana; TRÓCCOLI; Bartholomeu. Estereótipos de Gênero Aplicados a Mulheres Atletas. Psicologia: teoria e pesquisa, Brasília, v. 20, n. 3, p. 251-256, set./dez. 2004.

MOYA-MATA, Irene et al. Las imágenes de los libros de educación física de primaria desde la perspectiva de género. Tándem, didáctica de la educación física, Barcelona, n. 41, p. 41-48, 2013.

NEUENDORF, Kimberly A. Content analysis: A methodological primer for gender research. Sex Roles, New York, v. 64, n. 3-4, p. 276-289, 2011.

NOCERA, Pablo. La fotografia como metáfora en el pensamiento de Gabriel Tarde. Nómadas. Revista Crítica de Ciencias Sociales y Jurídicas, Madrid, v. 14, n. 2, p. 133-142, 2006.

OLIVEIRA, Sara. Texto visual, estereótipos de gênero e o livro didático de língua estrangeira.

Trabalhos em Linguística Aplicada, Campinas, v. 47, n. 1, p. 91-117, jun. 2008.

PARANÁ. Secretaria de Estado. Educação física: ensino médio. 2. ed. Curitiba: SEED-PR, 2007. Disponível em: <http://www.educadores.diaadia.pr.gov.br/arquivos/File/livro didatico/edfisica.pdf>. Acesso em: 17 nov. 2014.

PIRES, Suyan. Representações de gênero em ilustrações de livros didáticos. Psicopedagogia On Line, São Paulo, 2004. Disponível em: <http://www.psicopedagogia.com.br/artigos/artigo. asp?entrlD=608>. Acesso em: 7 abr. 2014.

RIO GRANDE DO SUL. Secretaria da Educação. Referenciais curriculares: caderno do aluno - $5^{\mathrm{a}} \mathrm{e}$ 6 a séries do ensino fundamental. Porto Alegre, 2009a. Disponível em: <http://www.educacao.rs.gov.br/ dados/refer curric aluno EF 56.pdf>. Acesso em: 17 nov. 2014.

RIO GRANDE DO SUL. Secretaria da Educação. Referenciais curriculares: caderno do aluno - $7^{a} e$ 8a Séries do Ensino Fundamental. Rio Grande do Sul, 2009b. Disponível em: <http://www.educacao. rs.gov.br/dados/refer_curric aluno EF_78.pdf>. Acesso em: 17 nov. 2014.

SALLES-COSTA, Rosana et al. Gênero e prática de atividade física de lazer. Cadernos de Saúde Pública, Rio de Janeiro, v. 19, p. S325-S333, 2003. supl. 2.

SÃO PAULO. Secretaria da Educação. Educação Física: cadernos do aluno. 5a-aㅗ Série Ensino Fundamental e 1a-3aㅡ Série Ensino Médio. São Paulo: CENP, 2010.

SCHWARTZ, Gisele Maria et al. Preconceito e esportes de aventura: A (não) presença feminina. Motricidade, Porto, v. 9, n.1, p. 57-68, mar. 2013.

SCOTT, Joan W. Gender: A useful category of historical analysis. The American Historical Review, Oxford, v. 91, n. 5, p.1053-1075, dez. 1986.

TÁBOAS-PAIS, María Inés. Análisis de los estereotipos corporales y de los modelos de actividad física representados en las imágenes de los libros de texto de Educación Física. 2009. 525 f. Tese (Doctorado en Didácticas Especiales, Educación Física y Deportiva) - Universidade de Vigo, Pontevedra, 2009. 
TÁBOAS-PAIS, María Inés; REY-CAO, Ana. Gender differences in physical education textbooks in Spain: a content analysis of photographs. Sex Roles, New York, v. 67, n. 7-8, p. 389-402, 2012.

VIDIELLA, Judit et al. Masculinidad hegemónica, deporte y actividad física. Movimento, Porto Alegre, v. 16, n. 4, p. 93-115, out./dez. 2010.

VILANOVA, Anna; SOLER, Susanna. Las mujeres, el deporte y los espacios públicos. Ausencias y protagonismos. Apunts: Educació Física i Esports, Barcelona, n. 91, p. 29-34, jan./mar. 2008.

WENETZ, Ileana; STIGGER, Marco Paulo. A construção do gênero no espaço escolar. Movimento, Porto Alegre, v. 12, n. 1, p. 59-80, jan./abr. 2006. 